\title{
$\begin{array}{ll}\text { Research Square } & \begin{array}{l}\text { Preprints are preliminary reports that have not undergone peer review. } \\ \text { They should not be considered conclusive, used to inform clinical practice, } \\ \text { or referenced by the media as validated information. }\end{array}\end{array}$
}

\section{A Comparative Study of Total Knee Arthroplasty Outcome for Stiff Knee with or without Sequential Antirheumatic Drug Treatment}

Cheng-Qi Jia

Medical School of Chinese PLA: Chinese PLA General Hospital https://orcid.org/0000-0003-1517-3804

Xiao-Rui Guan

541 General Hospital

Zhi-Lai Zhao

Liaocheng Veterans Hospital

Ji-Ying Chen

Chinese PLA General Hospital

Xiang Li ( $\sim$ lixiang_steve@163.com)

Chinese PLA General Hospital

\section{Research Article}

Keywords: Stiff Knee, Rheumatoid Arthritis, Ankylosing Spondylitis, Total Knee Arthroplasty, Sequential Antirheumatic Drug Treatment

Posted Date: July 28th, 2021

DOI: https://doi.org/10.21203/rs.3.rs-738689/v1

License: @) (7) This work is licensed under a Creative Commons Attribution 4.0 International License. Read Full License

Version of Record: A version of this preprint was published at Journal of Orthopaedic Surgery and Research on August 21 st, 2021. See the published version at https://doi.org/10.1186/s13018-021-02662-5. 


\section{Abstract}

Background

To evaluate influence of antirheumatic drug treatment on knee function of patients with stiff knee after total knee arthroplasty (TKA).

Methods

Twenty-seven patients (44 knees) of active RA (rheumatoid arthritis) or AS (ankylosing spondylitis) with stiff knee were included in this study. And they were divided into two groups according to continue antirheumatic drug treatment or not after TKA: the therapeutic group (16 patients, $27 \mathrm{knees)}$ and the controlled group (11 patients, 17 knees). The outcomes were assessed by Knee Society Score (KSS), Visual Analogue Scale (VAS), range of motion (ROM) (at week 6 , month 6, year 1 and year 2), "Forgotten Joint" Scale (FJS), with or without crutch, satisfaction and revision (at year 2). The knee prosthetic loosening was evaluated by the followed X-ray at each following time.

Results

The mean follow-up time was 51 months (34-69 months). The KSS were higher at week 6 after TKA in the therapeutic group ( $p<0.05)$, however, the functional scores of KSS at month 6, year 1 and year 2 in the controlled group were more points improved. The therapeutic patients preferred the knee more at month 6 , year 1 and year 2. The differences of KSS clinical scores (at month 6, year 1 and year 2), VAS, ROM, Crutch and FJS between the two groups were not statistically significant $(p \otimes 0.05)$.

Conclusion

For patients with stiff knees, the sequential antirheumatic drug treatment after TKA had no effect on postoperative KSS, but can improve the satisfaction.

Level of evidence

Therapeutic Level II. See Instructions for Authors for a complete description of levels of evidence.

\section{Introduction}

The amount of flexion achieved after total knee arthroplasty (TKA) is determined by the amount of preoperative flexion, especially if the flexion was less than $50^{\circ 1}$. Therefore, preoperative restriction of knee motion is a challenge for surgeons ${ }^{2}$.

Stiffness can be defined as limited range of motion (ROM) of $50^{\circ}$ or less that affects a patient's ability to perform activities of daily living. One study found patients require an average of $83^{\circ}$ knee flexion to climb stairs foot over foot. To sit in a chair without using one's hands requires $93^{\circ} \mathrm{knee}$ flexion on average, and tying one's shoes while seated requires $106^{\circ}$ flexion on average ${ }^{1}$.

There were some studies regarding results of primary TKAs in patients with a preoperative arc of motion of $50^{\circ}$ or less. From these literatures we knew that the surgical approach in these patients could be a challenge because of difficulty in patellar eversion. Technical problems include lack of adequate exposure, the need for extensile surgical approaches, the risk of patellar tendon avulsion, difficulty balancing the flexion-extension gaps, component malpositioning, extensor mechanism management, patellar maltracking, avulsion of the collateral ligaments, and difficulty in wound closure ${ }^{3}$. However, others have reported that postoperative ROM in patients with stiff knees can be the same as ROM in patients with flexible knees, and that there were low complication rates in these replaced knees ${ }^{4}$. Numerous studies had mainly focused on the stiff knee ${ }^{1}$, there may be a tendency to underestimate outcome for stiff knee with or without sequential drug treatment for rheumatoid and ankylosing spondylitis.

We asked whether the sequential antirheumatic drug after TKA influence knee function, ROM and satisfaction for stiff knees.

\section{Methods}

\section{Study design}

In clinical work, it was found that some patients with RA or AS after TKA had spontaneously stopped rheumatology drug treatment for economic reasons or autonomous activity. We collected 30 patients with stiff knee and started follow-up observation from week 6 after TKA, when the control group stopped all postoperative and anti-rheumatic drug treatment.

The inclusion criteria were as follows: 1 ) aged between 18 and $65 ; 2$ ) all surgical procedures were conducted by the same surgeon; 3 ) all patients had a preoperative flexion arc of $50^{\circ}$ or less in knees; and 4) a minimum follow-up period of 2 years. The exclusion criteria were as follows: 1 ) a history of septic arthritis of the knee or osteomyelitis; 2 ) any medical disability that limited the ability to walk and would not be considered suitable for a minimum 2-year follow-up period; 3 ) disabling diseases involving other joints of the lower extremities, and severe deformities (varus angulation, valgus angulation, or flexion contracture of more than $\left.15^{\circ}\right)$; 4) mental diseases; and 5) patients participating in other trials were excluded ${ }^{5}$.

These TKAs were performed by a senior author from January 2015 to October 2017. The patients were classified into two groups: Group 1 included stiff knees with sequential drug treatment after TKA (27 knees in 16 patients; bilateral in 11 patients, and unilateral in 5 patients; 3 patients lost to follow-up), and Group 2 included stiff knees without sequential drug treatment (17 knees in 11 patients; bilateral in 6 patients, and unilateral in 5 patients) (Fig 1).

Page 2/11 
We evaluated the patients preoperatively and postoperatively at intervals of 6 weeks, 6 months, 1 year, and yearly thereafter until the final follow-up. Preoperative and postoperative clinical evaluations were performed by two independent orthopaedic surgeons according to KSS, ROM, VAS, FJS and Crutch. Data results are cross-checked by the other two independent orthopaedic surgeons.

The preoperative data included the patient demographics (Table 1), ROM, KSS, and VAS (Table 1-4). There were 12 women and 15 men. 10 patients had simultaneous bilateral TKAs under one anesthesia. 7 patients had staged bilateral TKAs and 10 had a unilateral TKA.

The data of the operative data included operation time, intraoperative blood loss, prosthesis type, patella replacement and soft tissue and bone procedures (Table 2).

Postoperatively we not only studied the KSS, ROM, VAS, with or without crutch and radiographic data of patients, but also the revision rate, self-satisfaction and "Forgotten Joint" scale (FJS) (Table 1-5). Patients' satisfaction was classified as very good if they have no other uncomfortable feelings; Good if they have few special feelings; General if they could accept some uncomfortable feelings; Not good if they could not accept the uncomfortable feelings.

Radiographic evaluations of alignment were performed on preoperative and follow-up postoperative radiographs, which included anteroposterior (AP) standing, lateral, skyline patellar views and full length of lower limbs. The data were evaluated by another independent orthopaedic surgeon who did not know the patient's sequential drug treatment.

Data regarding the intraoperative and immediate postoperative complications were retrieved from the operating notes. Revision for any reason was documented.

\section{Operation procedures}

All patients received the total knee arthroplasty (Depuy PFC, Depuy RP, Depuy PS150, Link RK). The surgeries were performed by one senior physician under tourniquet control using a medial parapatellar approach. The posterior cruciate ligament was sacrificed because of severe deformity. We used an extramedullary alignment jig for the tibia and an intramedullary alignment jig for the femur. The patella was replaced in 11 knees (8 knees in group $1 ; 3$ knees in group 2). We performed a patelloplasty, which included soft tissue release from the lateral patella, division of the patellofemoral ligament, and patellar rim cautery to provide partial denervation and osteophyte removal. We removed 2-4 mm of the articular surface of the patella in TKA ${ }^{2}$.

We performed an extensile exposure (rectus snip) in knees to enable eversion of the patella and knee flexion. Soft tissue procedures included lateral retinacular release and lateral gutter debridement ${ }^{6}$. Extensive medial capsular sleeve dissection, including stripping the superficial medial collateral ligament, was performed in knees to correct the preoperative varus deformity. The iliotibial band was released from the Gerdy's tubercle in 3 knees with a preoperative valgus deformity. In 4 knees, we performed a quadriceps VY-plasty early during exposure to facilitate patellar eversion. The VY-plasty was repaired with the knee in $45^{\circ}$ flexion to prevent extension lag (Table 2). A subperiosteal femoral peel was needed in all knees. All knees required extensive posterior capsulotomy and subperiosteal elevation of the gastrocnemius from the posterior femur. Twenty three knees required an additional distal femoral cut (20 knees) or proximal tibia cut (2 knees) to correct the severe preoperative flexion deformity. Posterior stabilized components were used in 36 knees (20 Depuy PFC, 9 Depuy RP, 7 Depuy PS150), and a constrained condylar prosthesis (Link RK) was used in 8 knees, with an asymmetric laxity greater than $1 \mathrm{~cm}$ for the capsular and ligamentous insufficiency (Table 2). All patients had at least a $90^{\circ}$ arc of flexion after wound closure. The patella was fused to the anterior femur in 13 patients (Table 2), and was osteotomized and reflected laterally after the arthrotomy (Table 2). The tibiofemoral joint line was visible in all knees, even in patients with bony ankylosis. We performed the osteotomy along the joint line using a curved osteotome to separate the tibia and femur. We used precaution to preserve as much bone as possible, and to preserve the medial and lateral soft tissue sleeve.

Patients received antibiotic prophylaxis with intravenous Ceftriaxone Sodium ( $2 \mathrm{~g}, 30$ minutes before tourniquet followed by $2 \mathrm{~g}$ for the next day). If the operation time exceeds 3 hours or the blood loss is greater than $1500 \mathrm{ml}$, a second dose can be given during the operation. But no antithrombotic prophylaxis (according to the special blood state of RA and AS patients). The postoperative regimen included: intravenous and oral analgesia (oral until 6 weeks after TKA), knee extension training immediately, gravity-assisted regaining of flexion and walking with support from the second postoperative day. Progressive resistance exercises were started at day 2 postoperatively to strengthen the quadriceps and were continued for 1 year postoperatively. All patients used walker in 6 weeks postoperatively. The main drugs used in the sequential drug treatment group after TKA are: Methotrexate, Sulfasalazine, Tripterygium wilfordii, Steroid, Leflunomide, Non-steroidal anti-inflammation drugs, Etanercept and Root of herbaceous peony6.

\section{Statistical analysis}

SPSS 24.0 (SPSS Inc) was used for statistical analysis by an independent orthopaedic surgeon. Clinical data were analyzed using means \pm standard deviation or the median with the range in parentheses. The level of statistical significance was defined as $p<0.05$. Independent sample t-tests were performed to determine the difference in age and Body Mass Index (BMI). We used the Mann-Whitney test of nonparametric test for continuous variables when the data did not conform to the normal distribution, like the duration of hospital stay, operation time, blood loss, KSS, VAS, ROM and FJS. Chi-squared test or Fisher's exact probability test were for categorical variables, like satisfaction and Crutch.

\section{Results}

We observed no differences in revision rates between the two groups (Table 1). In group 1, there was 1 patient (2 knees) whose knee prosthesis were successively revised due to aseptic loosening at year 2 after the first TKA (Table 1). There were 3 cases of residual $15^{\circ}$ flexion deformity after TKA ( 1 in group I, 2 in group 2) (Table 2). 
The KSS in group 1 was higher than that in group 2 postoperatively at week $6(p<0.05)$ (Table 3$)$. However, the postoperative functional scores of KSS in patients with sequential drug treatment (group 1) were lower $(p<0.05)$ than that in patients without sequential drug treatment (group 2$)$ at month 6 , year 1 and year 2 (Fig.2). The clinical scores of KSS (at month 6, year 1 and year 2) between the two groups were not statistically significant ( $p \varangle 0.05$ ) (Fig.2).

The median preoperative flexion deformity was $10^{\circ}$ (range, $0^{\circ}-50^{\circ}$ ) in group 1 and $25^{\circ}$ (range, $0^{\circ}-50^{\circ}$ ) in group 2 , without statistically significant $(p=0.435$ ) (Table 4). Postoperatively, arc of motion at different following time in two groups were not statistically significant (p『0.05) (Fig.2).

The median preoperative VAS was 50 (range, 25-100) in group 1 and 75 (range, 25-75) in group 2, without statistically significant ( $p=0.335)$ (Table 4). Postoperatively, VAS at different following time in two groups were not statistically significant (p囚0.05) (Fig.2).

FJS at year 2 were 50 (range, 25-100) in group 1 and 75 (range, 25-75) in group 2 (Table 4). The difference between the two groups was not statistically significant $(p=0.335)$.

And the differences of Crutch between the two groups were not statistically significant $(p=0.231)$ (Table1). After TKA, there were 7 patients in the group of sequential anti-rheumatic drugs (group 1) who still used crutches at the 2-year follow-up, and 2 patients in the other group (group 2) (Table 1).

However, patients in group 1 were more satisfied than those in group 2 at month 6 , year 1 and year 2 after TKA $(p<0.05)($ Table 5). The imaging results are normal.

\section{Discussion}

Early treatment of RA and AS can effectively prevent joint destruction and improve the quality of life by controlling symptoms and inflammation. The main antirheumatic drugs used are: $₫$ Non-steroidal anti-inflammation drugs; $₫$ Glucocorticoids, local injection to treat refractory peripheral arthritis; $₫$ Rheumatology medication, the drugs recommended by the American Academy of Rheumatology classification standards mainly include sulfasalazine and methotrexate and leflunomide, etc.; $\varangle$ Biological agents, TNF antagonists are the first choice, which can improve the pain and function of the axial joints; $\varangle$ Thalidomide, special patients, when other related drugs have no effect, these drugs can significantly improve clinical symptoms ${ }^{7}$.

Due to severe pain, restricted mobility and deformities in patients with advanced RA and AS, medical treatment can no longer meet the needs of patients, then TKA is the best choice ${ }^{1}$. As patients with RA and AS have relatively young age, active lifestyles, and higher requirements for postoperative results, in addition to reasonable rehabilitation exercises, whether the continued use of drug therapy after surgery can improve knee joint function. To verify this idea, we conducted follow-up observations on these two types of patients.

Our series (44 stiff knees: 27 with sequential drug treatment versus 17 without sequential drug treatment knees) was the first series of TKAs in stiff patients with limited ROM of $50^{\circ}$ or less to verify this question. Our data observed that stiff knee patients with sequential antirheumatic drug treatment after TKA had a better clinical and functional outcome at week 6 after TKA than patients without antirheumatic drug treatment, but a lower scores in functional part of KSS at month 6 , year 1 and year 2 . The clinical scores of KSS at other following-up time were not statistically significant $(p \otimes 0.05)$.

We considered that under taking analgesia in both groups in week 6 after TKA, patients taking anti-rheumatic drugs at the same time had a greater degree pain relief and local inflammation control, thereby better improved their postoperative clinical and functional scores of KSS at week 6 after TKA. Then the two groups of patients stopped using conventional analgesics simultaneously, patients in group 1 continued anti-rheumatic drug treatment, and patients in group 2 stopped taking antirheumatic drugs due to economic problems or active exercise awareness. We believed that under economic pressure or active exercise awareness, their (in group 2) activity level would increase in order to recover quickly, which made them have a higher KSS functional scores at month 6, year 1 and year 2 after TKA. This situation was speculated to a certain extent that the amount of activity is related to the KSS after TKA.

There was not much published information regarding results of TKAs in knees with a preoperative arc of motion less than $50^{\circ}$. Aglietti and Buzzi (20 stiff knees, six ankylosed knees) reported ankylosed knees achieved less motion than stiff knees ${ }^{3}$. Montgomery et al reported no difference in the results after TKA when comparing ankylosed knees with knees of relatively normal motion ${ }^{2}$. Dr. Ashok Rajgopal (96 patients, 115 knees) reported the long-term functional outcome scores of stiff knees in extension and in flexion are similar ${ }^{8}$. However, no studies included stiff knee patients to accurately compare stiff knees with sequential antirheumatic drug treatment after TKA with those without to identify the functional improvement.

Postoperative arc of flexion ranging from $64^{\circ}-103^{\circ}$ had been reported in stiff and ankylosed knees in series ranging from 3 to 84 knees ${ }^{9}$. Our results were comparable to those of previous studies.

In our study the median postoperative arc of motion at different following time in two groups were not statistically significant ( $p \llbracket 0.05$ ) (Table 4), but the median and mean ROM of patients who did not use antirheumatic drugs (group 2) were both higher than those who used antirheumatic drugs (group 1 ) at month 6 , year1 and year 2 . This may indicate that patients who did not take antirheumatic drugs sequentially had greater mobility of their knee joints because of active rehabilitation activities.

Postoperatively, VAS at different following time in two groups were not statistically significant ( $p \llbracket 0.05)$ (Table 4). But the mean VAS in group 1 were higher than those in group 2 at month 6 , year1 and year 2 . This may indicate that patients with sequential use of antirheumatic drugs were more sensitive to pain, which limited their postoperative activity.

FJS at year 2 were 50 (range, 25-100) in group 1 and 75 (range, 25-75) in group 2 (Table 4) $(p=0.335)$. This may indicate that patients with sequential antirheumatic drug treatment after TKA did not make sense to forget joint replacement. 
In terms of higher satisfaction after TKA in patients with sequential drug treatment, we considered that patients who took antirheumatic drugs continually (at week 6, month 6, year 1 and year 2) after TKA would help relieve their general discomfort and control local inflammation (Table 5).

In addition, small bone sizes, severe osteopenia in a high proportion of patients with RA and AS, and severe soft tissue contractures made the operation technically demanding ${ }^{10}$. During exposure, stiff knees may need a rectus snip for exposure. Knees with osseous ankylosis in extension almost always need VY quadricepsplasty before the patella can be everted to minimize the risk of patellar tendon avulsion ${ }^{11}$. Aglietti and Buzzi recommended early quadricepsplasty to aid in exposure and patellar eversion without compromising the integrity of the patellar tendon ${ }^{3}$. We performed early quadricepsplasty in 4 knees with osseous ankylosis in extension. Twenty knees underwent plus osteotomy on the femoral side and three knees underwent plus osteotomy on the tibial side. One patient underwent quadriceps garter treatment. Three cases of knee joints underwent iliotibial band lysis. All patients underwent subperiosteal dissection.

A constrained total knee prosthesis has been recommended for converting a fused knee to a TKA to substitute for deficient or absent collateral ligaments ${ }^{12}$, in our experience, posterior-stabilized prostheses were also performed successfully in patients with stiff knees.

McAuley et al evaluated 27 TKAs in patients with a preoperative range of flexion less than $50^{\circ}$. They reported an overall complication rate of $41 \%$ with a revision rate of $18.5 \%$. Similar high complication and revision rates were reported by Naranja et al in patients who had TKAs for ankylosed knees ${ }^{13}$. The overall revision rate in our series (2.27\%) was lower than rates in previous studies.

Our study has several limitations. The primary limitation is that the study lacked adequate power to compare the results of TKAs in patients with knees ankylosed in extension with the results in patients with knees ankylosed in flexion. The other limitation is that several prostheses were used during the study, and the comparison of results based on the implant used also would be prone to inadequate power. To sit in a chair without using one's hands requires $93^{\circ}$ knee flexion on average, and tying one's shoes while seated requires $106^{\circ}$ flexion on average, more cases are needed for subgroup analysis from the two angles ${ }^{8}$.

Our results were inferior to results of a standard primary TKA and had a lower KSS and FJS ${ }^{14}$. The surgery is technically demanding and should be performed only by a surgeon with considerable experience. Patients need to be counseled preoperatively regarding the possibility of a suboptimal outcome compared with that of a standard TKA performed in a mobile knee, the need for prolonged physiotherapy, more activity and higher tolerance, and the high complication rate.

In conclusion, for patients with stiff knees, the sequential antirheumatic drug treatment after TKA had no effect on postoperative KSS, but can improve the satisfaction. And according to the result of a higher postoperative functional values of KSS in patients without sequential drug treatment, we considered more postoperative activity or active awareness can improve postoperative function. We recommend patients with RA or AS undergo more activity in time after TKA.

\section{Conclusion}

For patients with stiff knees, the sequential antirheumatic drug treatment after TKA had no effect on postoperative KSS, but can improve the satisfaction.

\section{Abbreviations}

RA, rheumatoid arthritis; AS, ankylosing spondylitis; TKA, total knee arthroplasty; NSAIDS, non-steroidal anti-inflammatory drugs; KSS, knee society score; BMI, body mass index; ROM, range of motion; VAS, visual analogue scale; FJS, "Forgotten Joint" scale; AP standing, anteroposterior standing.

\section{Declarations}

\section{Consent for publication}

Not applicable.

\section{Availability of data and materials}

We do not wish to share our data, because some of the patient's data regarding individual privacy, and according to the policy of our hospital, the data could not be shared with others without permission.

\section{Conflict of interest}

Each author certifies that he or she has no commercial associations (eg, consultancies, stock ownership, equity interest, patent/licensing arrangements, etc) that might pose a conflict of interest in connection with the submitted article.

\section{Competing interests}

The authors declare that they have no competing interests.

\section{Funding}

This study was funded by the National Key Research and Development Program of China [No. 2020YFC2004900]. 
Authors' contributions

\begin{tabular}{|c|c|}
\hline Contributors & Roles \\
\hline CJ & $\begin{array}{l}\text { Manuscript writing; Data collection; Data analysis; Study conceive; Participated in the design of the study; Data interpretation; Project } \\
\text { coordination }\end{array}$ \\
\hline XG & Data collection; Data analysis; Study conceive; Participated in the design of the study; Data interpretation; Project coordination \\
\hline $\mathrm{ZZ}$ & Data curation; Investigation; Methodology; Validation; Writing - review \& editing \\
\hline JC & Project administration; Supervision; Writing - review \& editing \\
\hline$X L$ & Project administration; Supervision; Writing - review \& editing \\
\hline
\end{tabular}

\section{Acknowledgments}

We thank Drs. Ji-Yuan Dong, Yong-Gang Zhou, Li-Bo Hao, Wei Chai, Qiang Lu, Guo-Qiang Zhang, Ming Ni, Jun Fu, Chi Xu, Bao-Zhan Yu, Rui Li, Xiang-Peng Kong and all staff from the participating departments and clinics for their help in performing aspiration in these years and for their help with patients enrollment and data collection.

\section{References}

1. Kim Y-H, Kim J-S. Does TKA Improve Functional Outcome and Range of Motion in Patients with Stiff Knees? Clin Orthop. 2009;467(5):1348. doi:10.1007/s11999-008-0445-7.

2. W H Montgomery 3rd 1, J N Insall, S B Haas, M S Becker, R E Windsor, Primary total knee arthroplasty in stiff and ankylosed knees. The American Journal of Knee Surgery. 1998;11(1):20-3.

3. Paolo Aglietti, Russell E. Windsor, Roberto Buzzi, John N. Insall. Arthroplasty for the Stiff or Ankylosed Knee . The Journal of Arthroplasty. 1989;4(1).

4. Jp M, Mf H, D A, Ga E. Outcome of knee arthroplasty in patients with poor preoperative range of motion. Clinical orthopaedics and related research. 2002 Nov;(404):203-7. doi:10.1097/00003086-200211000-00033.

5. Emrah KovalaK1, ata Can, neşe StEgEmann, ayşe Övül Erdoğan, Fahri Erdoğan. Total knee arthroplasty after osseous ankylosis of the knee joint. Acta Orthop Traumatol Turc. 2015;49(5):503-507. doi:10.3944/AOTT.2015.14.0304.

6. Asai S, Takahashi N, Asai N, et al. Characteristics of patients with rheumatoid arthritis undergoing primary total joint replacement: A 14-year trend analysis (2004-2017). Mod Rheumatol. 2020;30(4):657-663. doi:10.1080/14397595.2019.1649111.

7. Susan M Goodman, Michael D George. "Should we stop or continue conventional synthetic (including glucocorticoids) and targeted DMARDs before surgery in patients with inflammatory rheumatic diseases?" RMD open. 2020;6:e001214. doi:10.1136/rmdopen-2020-001214.

8. Ashok Rajgopal, Inayat Panda, Vivek Dahiya, Vivek Dahiya. A Comparative Study on the Long-Term Outcome of Total Knee Arthroplasty Performed for Knees Stiff in Extension and Those Stiff in Flexion. The Journal of Arthroplasty. 2017 Nov;32(11):3396-3403. doi: 10.1016/j.arth.2017.06.027.

9. S. Bhan, R. Malhotra, E. Krishna Kiran. Comparison of total knee arthroplasty in stiff and ankylosed knees. Clinical orthopaedics and related research. 2006;451:87-95. doi:10.1097/01.blo.0000229313.20760.13

10. Caroline Debette, Sébastien Lustig, et al. Total knee arthroplasty of the stiff knee three hundred and four cases. International Orthopaedics (SICOT). 2014;38:285-289. doi:10.1007/s00264-013-2252-3.

11. Willem Alexander Kernkamp, Wiebe Christiaan Verra, et al. Conversion of a Surgically Arthrodesed Knee to a Total Knee Arthroplasty Is it Worth it A Meta Analysis. International Orthopaedics (SICOT). 2016;40:2069-2074. doi:10.1007/s00264-016-3150-2.

12. Paul J. H. van Rensch, Petra J. C. Heesterbeek, Gerjon Hannink, Gijs G. van Hellemondt, Ate B. Wymenga. Improved clinical outcomes after revision arthroplasty with a hinged implant for severely stiff total knee arthroplasty. Knee Surgery, Sports Traumatology, Arthroscopy. 2019;27:1043-1048.

https://doi.org/10.1007/s00167-018-5235-5.

13. R J Naranja Jr, P A Lotke, M W Pagnano, A D Hanssen. Total knee arthroplasty in a previously ankylosed or arthrodesed knee. Clinical orthopaedics and related research. 1996 Oct;(331):234-7. doi:10.1097/00003086-199610000-00033.

14. Nikolaou VS. Common controversies in total knee replacement surgery: Current evidence. World J Orthop. 2014;5(4):460. doi:10.5312/wjo.v5.i4.460.

\section{Tables}

Table.1 Patient Demographic Parameters. 


\begin{tabular}{|c|c|c|c|}
\hline Parameters & $\begin{array}{l}\text { Drug Treatment } \\
(\mathrm{N}=16,27 \text { knees })\end{array}$ & $\begin{array}{l}\text { No Drug Treatment } \\
\text { (N=11, } 17 \text { knees) }\end{array}$ & $p$ Value \\
\hline Aget (yr) & $39.56 \pm 11.74$ & $38.64 \pm 9.21$ & 0.828 \\
\hline Gender & & & 0.696 \\
\hline Male (no.[\%]) & $8(50 \%)$ & $7(63.63 \%)$ & \\
\hline Female (no.[\%]) & $8(50 \%)$ & $4(36.36 \%)$ & \\
\hline Heightt(cm) & $163.94 \pm 12.15$ & $162.82 \pm 8.32$ & 0.793 \\
\hline Weightt ( kg) & $62.29 \pm 15.61$ & $54.00 \pm 8.34$ & 0.121 \\
\hline $\operatorname{BMl}+\left(\mathrm{kg} / \mathrm{m}^{2}\right)$ & $22.97 \pm 4.15$ & $20.44 \pm 3.25$ & 0.102 \\
\hline Diagnosis & & & 1.000 \\
\hline Rheumatoid arthritis & 9 & 7 & \\
\hline Ankylosing spondylitis & 7 & 4 & \\
\hline Knee & & & 0.548 \\
\hline Left Knee & 13 & 10 & \\
\hline Right Knee & 14 & 7 & \\
\hline Bilateral TKAs & 11 & 6 & \\
\hline Unilateral TKA & 5 & 5 & \\
\hline Inpatient Dayst+ (d) & $13.5(6-29)$ & $12(7-28)$ & 0.568 \\
\hline Follow-uptt (mo) & $46.5(35-69)$ & $58(34-69)$ & 0.138 \\
\hline Crutch (no.[\%]) & & & 0.231 \\
\hline With Crutch & $7(43.75 \%)$ & $2(18.18 \%)$ & \\
\hline Without Crutch & $9(56.25 \%)$ & $9(81.82 \%)$ & \\
\hline Revision knee (no.[\%]) & $2(2 / 44,2.27 \%)$ & 0 & 1.000 \\
\hline
\end{tabular}

$\mathrm{BMI}=$ body mass index.

†The values are given as the mean and the standard deviation

††The values are given as the median, with the range in parentheses

Table.2 Comparison of Operative Data between two groups after TKA. 


\begin{tabular}{|llll|}
\hline Operative Data & $\begin{array}{l}\text { Drug Treatment } \\
(\mathrm{N}=16,27 \text { knees })\end{array}$ & $\begin{array}{l}\text { No Drug Treatment } \\
(\mathrm{N}=11,17 \text { knees })\end{array}$ & $p$ Value \\
\hline Surgical timett (minutes) & $122.5(60-240)$ & $127.5(62.5-285)$ & 0.904 \\
\hline Blood losstt $(\mathrm{mL})$ & $300(50-600)$ & $250(50-600)$ & 0.565 \\
ASA & & & 0.624 \\
II & 13 & 10 & \\
III & 3 & 1 & 0.333 \\
\hline Prosthesis & & & \\
\hline Depuy PFC & 11 & 9 & \\
Depuy PS150 & 6 & 1 & \\
Depuy RP & 4 & 5 & \\
Link RK & 6 & 2 & \\
Patella replacement (no.[\%]) & $8(28.57 \%)$ & $3(17.65 \%)$ & \\
Soft tissue and bone procedures & & 2 & \\
The fused knee & 8 & 5 & \\
VY Quadricepsplasty & 4 & 0 & \\
Iliotibial band lysis & 3 & 2 & \\
Plus osteotomy (Femoral) & 12 & & \\
Plus osteotomy (Tibia) & 0 & & \\
Residual flexion deformity (no.[ degree] $)$ & $1\left(15^{\circ}\right)$ & & \\
\hline
\end{tabular}

†十The values are given as the median, with the range in parentheses.

Table.3 Comparison of KSS score between two groups after TKA.

\begin{tabular}{|c|c|c|c|c|c|c|c|c|c|}
\hline \multirow[t]{2}{*}{ Group } & \multicolumn{4}{|c|}{ Clinical score } & \multicolumn{5}{|c|}{ Functional score } \\
\hline & Preoperative & $\begin{array}{l}\text { Postoperative } \\
\text { at week } 6\end{array}$ & $\begin{array}{l}\text { Postoperative } \\
\text { at month } 6\end{array}$ & $\begin{array}{l}\text { Postoperative } \\
\text { at year } 1\end{array}$ & $\begin{array}{l}\text { Postoperative } \\
\text { at year } 2\end{array}$ & Preoperative & $\begin{array}{l}\text { Postoperative } \\
\text { at week } 6\end{array}$ & $\begin{array}{l}\text { Postoperative } \\
\text { at month } 6\end{array}$ & $\begin{array}{l}\mathrm{P} \\
\mathrm{a}\end{array}$ \\
\hline $\begin{array}{l}\text { Drug } \\
\text { Treatmenttt }\end{array}$ & $9(0-69)$ & $0(0-5)$ & $83(56-99)$ & $83(56-99)$ & 85 (37-99) & $73(32-84)$ & $5(0-70)$ & $55(5-100)$ & 6 \\
\hline $\begin{array}{l}\text { No Drug } \\
\text { Treatmentt† }\end{array}$ & $0(0-52)$ & $5(0-5)$ & $89(53-99)$ & $89(52-99)$ & $89(52-99)$ & $54(32-78)$ & $0(0-55)$ & $100(0-100)$ & 1 \\
\hline Statistic & $p=0.084$ & $p=0.026^{*}$ & $p=0.068$ & $p=0.068$ & $p=0.184$ & $p=0.10$ & $p=0.026^{*}$ & $p=0.002^{*}$ & $p$ \\
\hline
\end{tabular}

†十The values are given as the median, with the range in parentheses. ${ }^{*} p[0.05$.

Table.4 Comparison of ROM, VAS and FJS between two groups after TKA.

\begin{tabular}{|c|c|c|c|c|c|c|c|c|c|}
\hline \multirow[t]{2}{*}{ Group } & \multicolumn{5}{|c|}{ ROM } & \multicolumn{4}{|c|}{ VAS } \\
\hline & Preoperative & $\begin{array}{l}\text { Postoperative } \\
\text { at week } 6\end{array}$ & $\begin{array}{l}\text { Postoperative } \\
\text { at month } 6\end{array}$ & $\begin{array}{l}\text { Postoperative } \\
\text { at year } 1\end{array}$ & $\begin{array}{l}\text { Postoperative } \\
\text { at year } 2\end{array}$ & Preoperative & $\begin{array}{l}\text { Postoperative } \\
\text { at week } 6\end{array}$ & $\begin{array}{l}\text { Postoperative } \\
\text { at month } 6\end{array}$ & $\begin{array}{l}\mathrm{P} \\
\mathrm{a}\end{array}$ \\
\hline \multirow{2}{*}{$\begin{array}{l}\text { Drug } \\
\text { Treatment+t }\end{array}$} & 10 & 90 & 85 & 80 & 80 & 6 & 3 & 0 & 0 \\
\hline & $(0-50)$ & $(30-95)$ & $(30-110)$ & $(30-110)$ & $(30-110)$ & $(0-9)$ & $(0-9)$ & $(0-5)$ & $(1$ \\
\hline No Drug & 25 & 90 & 90 & 90 & 90 & 6 & 3 & 0 & 0 \\
\hline Treatment+t & $(0-50)$ & $(60-90)$ & $(60-90)$ & $(60-90)$ & $(70-90)$ & $(3-9)$ & $(0-6)$ & $(0-4)$ & $(1$ \\
\hline Statistic & $p=0.435$ & $p=0.658$ & $p=0.627$ & $p=0.332$ & $p=0.284$ & $p=0.335$ & $p=0.188$ & $p=0.065$ & $p$ \\
\hline
\end{tabular}


t†The values are given as the median, with the range in parentheses.

Table.5 Comparison of FJS and the patients' satisfaction between two groups after TKA (No.[\%]).

\begin{tabular}{|c|c|c|c|c|c|}
\hline \multirow[t]{2}{*}{ Group } & \multicolumn{4}{|c|}{ Patients' satisfaction } & \multirow[b]{2}{*}{$\begin{array}{l}\text { Postoperative } \\
\text { at year } 2\end{array}$} \\
\hline & Grade & $\begin{array}{l}\text { Postoperative } \\
\text { at week } 6\end{array}$ & $\begin{array}{l}\text { Postoperative } \\
\text { at month } 6\end{array}$ & $\begin{array}{l}\text { Postoperative } \\
\text { at year } 1\end{array}$ & \\
\hline \multirow[t]{4}{*}{ Drug Treatment } & Very good $\boldsymbol{t}$ & $1(1 / 27)$ & $1(1 / 27)$ & $1(1 / 27)$ & $1(1 / 27)$ \\
\hline & Goodt & $15(15 / 27)$ & $11(11 / 27)$ & $11(11 / 27)$ & $11(11 / 27)$ \\
\hline & Generalt & $11(11 / 27)$ & $13(13 / 27)$ & $13(13 / 27)$ & $13(13 / 27)$ \\
\hline & Not goodt & $0(0 / 27)$ & $2(2 / 27)$ & $2(2 / 27)$ & $2(2 / 27)$ \\
\hline \multirow[t]{4}{*}{ No Drug Treatment } & Very goodt & $0(0 / 17)$ & $0(0 / 17)$ & $0(0 / 17)$ & $0(0 / 17)$ \\
\hline & Goodt & $8(8 / 17)$ & $2(2 / 17)$ & $2(2 / 17)$ & $2(2 / 17)$ \\
\hline & Generalt & $6(6 / 17)$ & $4(4 / 17)$ & $4(4 / 17)$ & $4(4 / 17)$ \\
\hline & Not goodt & $3(3 / 17)$ & $11(11 / 17)$ & $11(11 / 17)$ & $11(11 / 17)$ \\
\hline Statistic & & $p=0.00^{*}$ & $p=0.035^{\star}$ & $p=0.00 *$ & $p=0.00 *$ \\
\hline
\end{tabular}

†These indexes of the patients' satisfaction were classified as Very Good if they have no other uncomfortable feelings; Good if they have few special feelings; General if they could accept some uncomfortable feelings; Not Good if they could not accept the uncomfortable feelings. * p $\varangle 0.05$.

Table.6 The Sequential Drug Treatment of Group 1 after TKA.

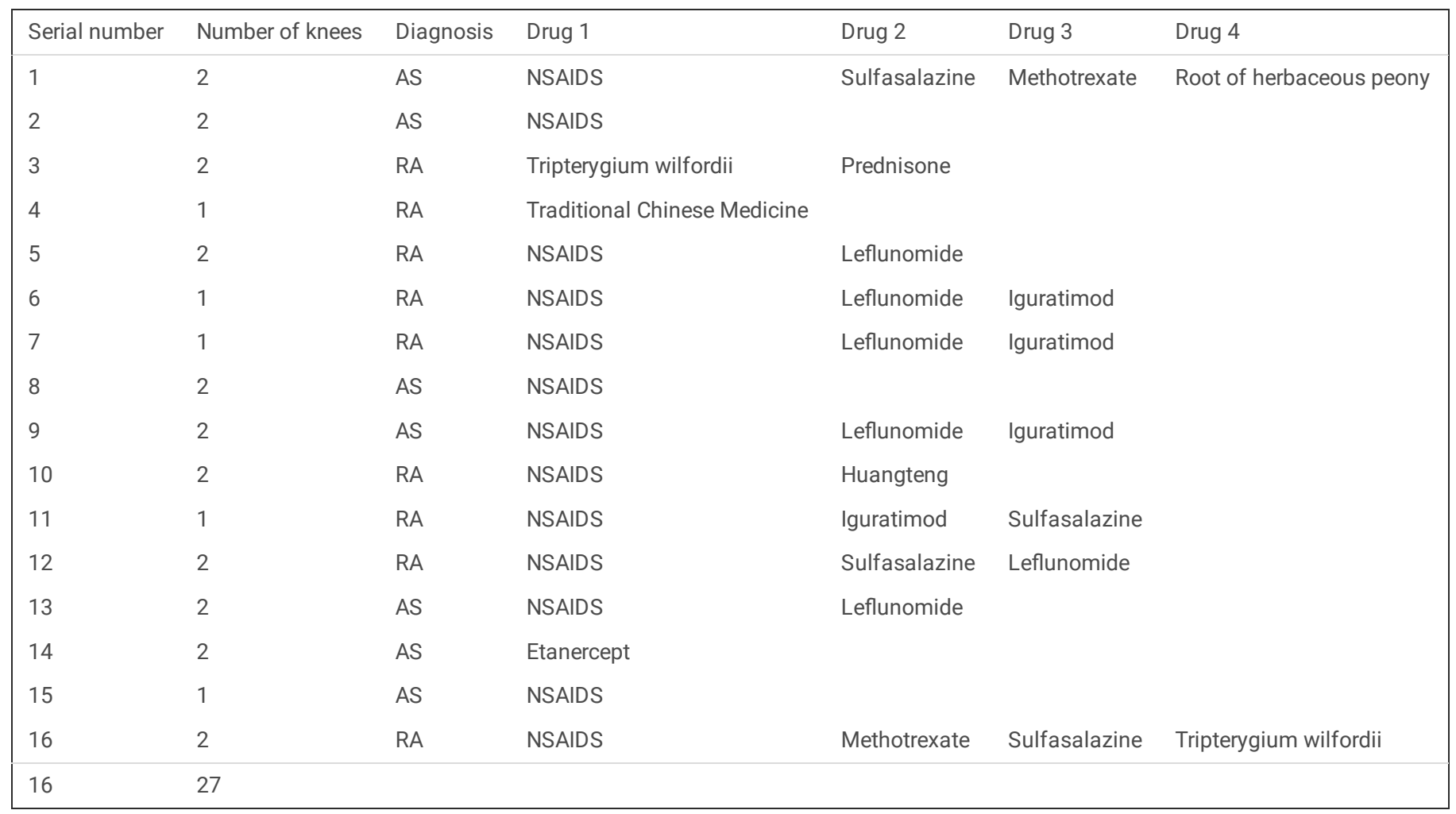

RA: Rheumatoid Arthritis; AS: Ankylosing Spondylitis; NSAIDS: Non-steroidal Anti-inflammatory drugs.

\section{Figures}




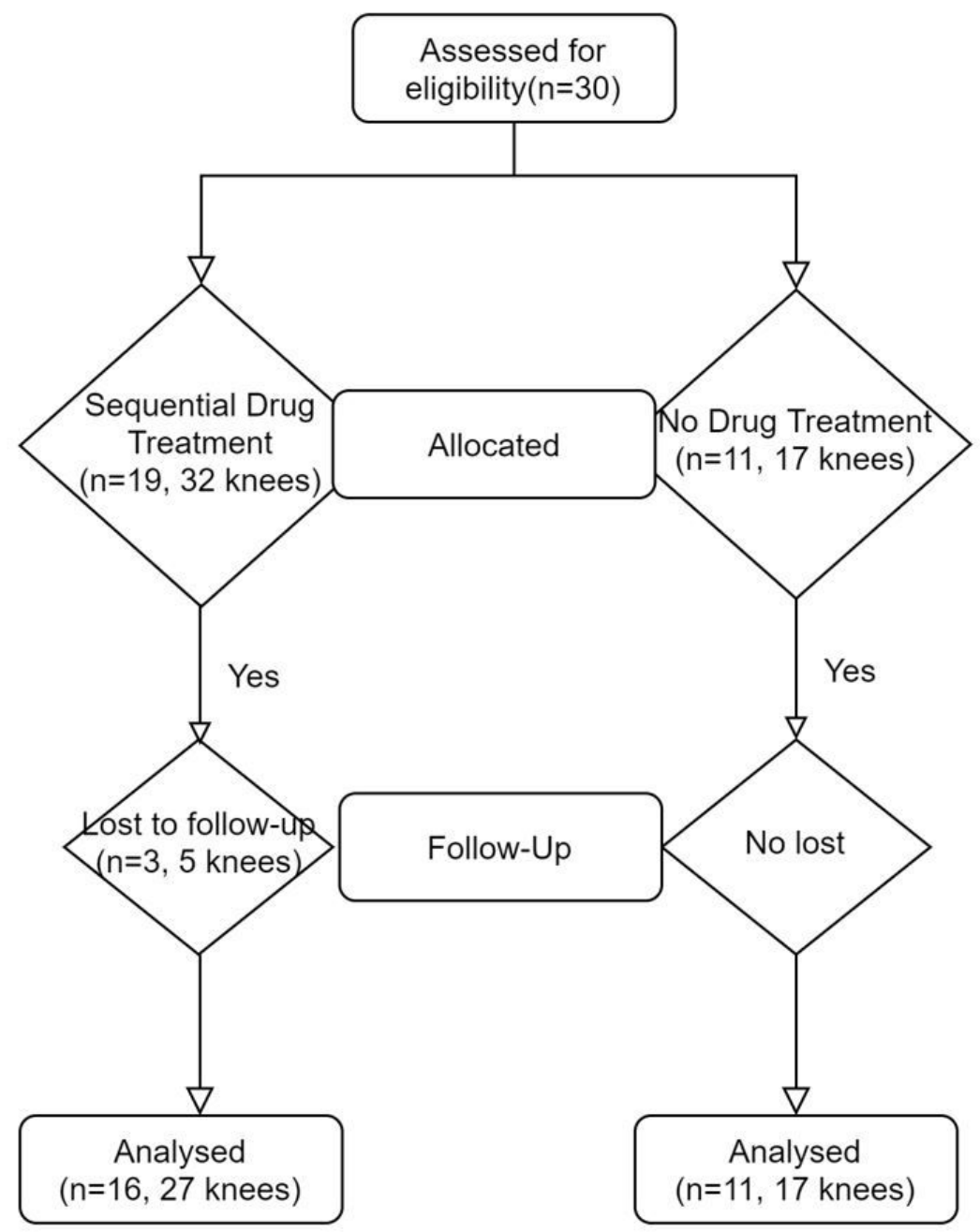

Figure 1

Flow Diagram 
- Sequential drug treatment

- No sequential drug treatment

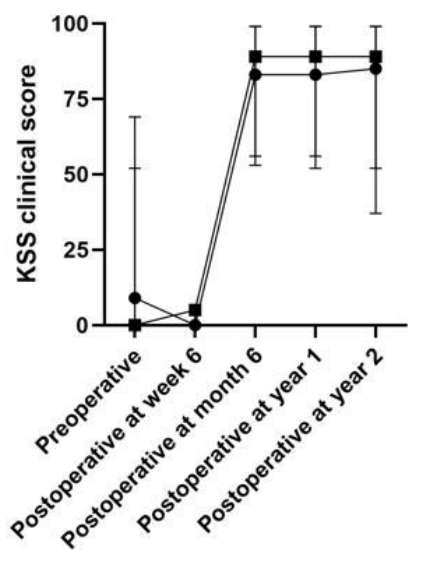

- Sequential drug treatment

- No sequential drug treatment

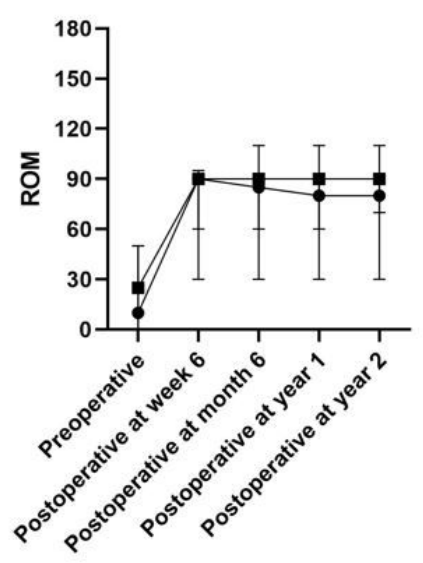

- Sequential drug treatment

- No sequential drug treatment

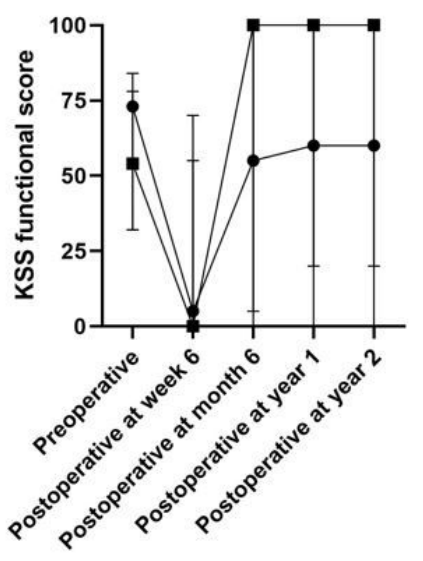

- Sequential drug treatment

- No sequential drug treatment

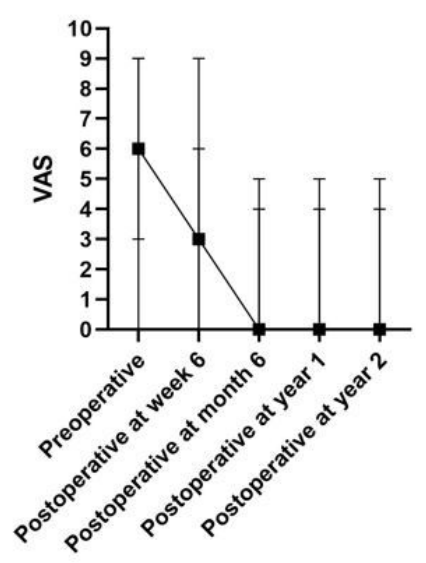

Figure 2

Changes in KSS, ROM and VAS at different following-up time 